\title{
Vitamin D, Neurosteroids and Autism
}

\author{
L. MÁČOVÁ ${ }^{1}$, M. BIČÍKOVÁ ${ }^{1}$, D. OSTATNÍKOVÁ ${ }^{2}$, M. HILL ${ }^{1}$, L. STÁRKA $^{1}$ \\ ${ }^{1}$ Institute of Endocrinology, Prague, Czech Republic, ${ }^{2}$ Institute of Physiology, Faculty of Medicine, \\ Comenius University, Bratislava, Slovak Republic
}

Received April 24, 2017

Accepted May 11, 2017

\begin{abstract}
Summary
Vitamin $D$ had been for a long time investigated for its effects on bone metabolism. Recently has been observed that the incidence of some neurodevelopmental disorders (including autism) increases hand in hand with vitamin D deficiency. Indeed, vitamin $D$ was reported to modulate the biosynthesis of neurotransmitters and neurotrophic factors; moreover, its receptor was found in the central nervous system. Vitamin D deficiency was therefore assessed as a risk factor for autism, however the biological mechanism has not yet been revealed. In our review we focused on potential connections among vitamin D, steroids and autism. Potential mechanisms of vitamin $\mathrm{D}$ action are also discussed.
\end{abstract}

\section{Key words}

Vitamin D • Neurosteroids • Autism • ASD • Autoimmunity

\section{Corresponding author}

L. Máčová, Department of Steroid Hormones, Institute of Endocrinology, Národní 8, 11694 Prague 1, Czech Republic. E-mail: Imacova@endo.cz

\section{Introduction}

The rapid increase of the prevalence of neuropsychiatric disorders suggests that less active indoor lifestyle and exposure to chemicals may impact the development of these diseases. Following chemicals or nutrients took attention to their association with neuropsychiatric disorders: smoke/tobacco, alcohol, air pollution, pesticides, endocrine-disrupting chemicals, heavy metals, micronutrients, fatty acid, and parental obesity as a proxy of accumulation of specific chemicals or nutritional status. Several chemical exposures may possibly be associated with an increased risk of neuropsychiatric disorders, whereas other traditional risk factors are less likely to be associated with the development of these diseases (Fujiwara et al. 2016). In our review we focus on vitamin D that is without any exaggeration contemporary phenomenon mentioned in connection with likely all areas of human health ranged from bone and glucose metabolism to mental health.

\section{Vitamin D as a hormone}

Vitamin D is an active steroid obtained by dietary uptake or synthesized in human skin from provitamin 7-dehydrocholesterol after the sunlight exposure. Further transformation, the first in the liver and then in the kidney yields hydroxyderivatives prehormone calcidiol $(1(\mathrm{OH}) \mathrm{D})$ and hormonally active calcitriol $\left(1,25-(\mathrm{OH})_{2} \mathrm{D}\right)$ and more than 35 structurally related less active hydroxycompounds. 1,25- $(\mathrm{OH})_{2} \mathrm{D}$ binds to the vitamin $\mathrm{D}$ receptors (VDR), thereby activating this receptor and regulating gene transcription. Concomitantly, non-genomic mechanisms of D-vitamin action that may involve L-type calcium channels have influence on brain function (Cui et al. 2015).

More than $85 \%$ of circulating vitamin D metabolites are tightly bound to vitamin D-binding protein (VDBP) and only the fraction not bound to VDBP (free and albumin-bound vitamin D) is believed to be biologically active (Bhan et al. 2012). VDBP levels rise under certain conditions such as pregnancy (Bikle et al. 1984) and Alzheimer's disease (Rinaldi et al. 2015) whereas decreased levels of VDBP were found for 
example in hepatic diseases (Bikle et al. 1984).

Sometimes misunderstandings arise because the studies of ingested vitamin $\mathrm{D}$ do not distinguish among animal cholecalciferol (vitamin $\mathrm{D}_{3}$ ) and ergocalciferol (vitamin $\mathrm{D}_{2}$ ) that is plant origin and other forms of vitamin D. Level of plasma calcidiol is considered to be the optimal indicator of vitamin D status; however, biologically active form of vitamin D is calcitriol. A method for assessing vitamin D status has not yet been standardized.

\section{Vitamin D and the brain}

In addition to maintaining calcium/phosphate homeostasis, vitamin D promotes several health benefits including neuroprotective effects, especially by antioxidant activity, neuronal calcium regulation, neurotransmitter regulation, influence on several neurotrophic factors and immunomodulation. Vitamin D deficiency leads to disturbance of these processes and may be involved in the development of autism. It seems likely that vitamin D exerts the strongest effects on nervous system during the prenatal development and early infancy, but also relate to the adult subject's mental state. The exact mechanism is waiting to be revealed, however, steroid hormones, vitamin D, their direct as well as epigenetic effects are presumably implicated in these processes.

The VDR and the enzyme $1 \alpha$-hydroxylase are also expressed in other tissues, including neuronal and glial cells (Eyles et al. 2005). There is evidence that vitamin $\mathrm{D}$ has a neuroprotective effect on brain function.

Calcitriol 1,25-(OH $)_{2} \mathrm{D}$ inhibits the synthesis of inducible nitric oxide synthase (iNOS), which catalyzes nitric oxide, a free radical that can damage cells (Garcion et al. 2002). 1,25-(OH $)_{2} \mathrm{D}$ also stimulates $\gamma$-glutamyl transpeptidase activity, which is important in the synthesis of glutathione, an antioxidant and free radicals scavenger. In addition, vitamin D may act as a neurotrophic factor.

Already three decades ago it was shown (Naveilhan et al. 1996) that vitamin D stimulates brain cells to produce several growth factors, like nerve growth factor (NGF), glial cell line-derived neurotrophic factor (GDNF) and neurotrophin 3 (NT3). These neurotrophic and neuroprotective actions of vitamin D suggest that this vitamin can stimulate the protection and growth of neuronal cells. Therefore, vitamin D may slowdown the progression of neurodegenerative diseases.
In the brain, vitamin $\mathrm{D}$ has important roles in proliferation and differentiation, calcium signaling and neurotrophic and neuroprotective actions; it may also alter neurotransmission and synaptic plasticity. An increasing number of epidemiological studies indicate that vitamin $\mathrm{D}$ deficiency is associated with a wide range of neuropsychiatric disorders and neurodegenerative diseases (Groves et al. 2014, Kesby et al. 2011, Rimmelzwaan et al. 2016). There is robust evidence from rodent experiments indicating that transient developmental vitamin D deficiency is associated with changes in brain structure, neurochemistry, gene and protein expression and behavior. So the timing and duration of vitamin D deficiency in the 'critical window' of the development is decisive, however, it has not yet been properly defined (Cui et al. 2015). Based on animal models is speculated, that with regard to neurodevelopmental disorders the last trimester may be in humans the period most sensitive to low prenatal vitamin D (O'Loan et al. 2007). It is of interest that this critical window overlap a sensitive window for brain morphological alterations driven by gonadal steroids (McCarthy 2008).

\section{Autistic spectrum disorder - ASD}

Autism or autistic spectrum disorder (ASD) comprises wide range of neurodevelopmental disorders characterized by problems with social skills, repetitive behaviors, speech and nonverbal communication, as well as by unique abilities. According to Diagnostic and Statistical Manual of Mental Disorders version 5 (DSM-5), ASD includes autistic disorder, childhood disintegrative disorder, pervasive developmental disorder-not otherwise specified (PDD-NOS) and Asperger's syndrome. In Czech Republic as well as in other countries, slightly different International Statistical Classification of Diseases and Related Health Problems version 10 (ICD-10) by the World Health Organization (WHO) is used for autism classification and diagnosis.

ASD has currently gained the characteristics of epidemic diseases. It was recently documented that the incidence of autism has grown by $700 \%$ since the 1970 s (Elsabbagh et al. 2012). Actual prevalence according to CDC (Centers for Disease Control and Prevention) is $1: 68$ and the cause of this increase is unknown.

ASD is a neurodevelopmental disorder, involving both genetic and environmental risk factors. Autism has been associated with more than 440 gene 
variants, however, about $70 \%$ of cases have a cause that has not been linked directly to genetics (Schaaf and Zoghbi 2011). The disease is characterized by primarily behavioral symptoms and includes impaired reciprocal social interactions, communication deficits, and propensity for repetitive behaviors. The diagnosis is very difficult given to behavioral nature of the symptoms and heterogeneity of neurodevelopmental disturbances that are characteristic for the disease.

Current diagnosis is based on questionnaires, which are usually completed by parents or guardians (Ostatnikova 2010, Ostatnikova 2015). To date there is no biological or laboratory marker proving or disproving autism. Even genetic testing shows gene variants that only affect autism risk and cannot account for autism appearance. The autism cannot be recognized even by any physical features. The average age of newly detected patients is 4.51 years, but experts believe that the first symptoms of the disease appear about $12^{\text {th }}$ month of age and the screening tests can be performed at age $16^{\text {th }}$ to $18^{\text {th }}$ months. Early and accurate diagnosis then leads to early intervention and better prognosis for the patient with autism.

\section{Vitamin D and autism}

Vitamin D plays crucial neuroprotective roles in the developing brain. Its deficiency has been reported in neuropsychiatric disorders as autism, depression, multiple sclerosis, Alzheimer's disease, Parkinson's disease, attention deficit hyperactivity disease etc. It has an important role in cell proliferation and differentiation, immunomodulation, regulation of neurotransmission and steroidogenesis. The effects of vitamin $\mathrm{D}$ on brain development, adult brain function and the links between low levels of vitamin D and neuropsychiatric disease were described in a handful of papers (Eyles et al. 2013). Animal studies have suggested that transient prenatal vitamin $\mathrm{D}$ deficiency is associated with altered brain development. The potential neurobiological mechanisms linking prenatal vitamin D deficiency and autism were reviewed recently (Ali et al. 2016).

Cannell (2008) was the first to propose that vitamin $\mathrm{D}$ reduced risk of autism. He based that assertion in part on higher prevalence of autism in regions with lower sunlight, whether due to latitude or clouds. A later paper reported higher autism rates in regions of the U.S. West Coast with higher precipitation rates (Grant 2016). Children with autism generally have lower vitamin D concentrations as has been already reviewed (Cannell and Grant 2013, Kocovska et al. 2012). A recent ecological study of autism prevalence among those aged 6-17 years found significant inverse correlations with respect to solar UVB doses (Grant and Cannell 2013). A study in Australia found that maternal 25 hydroxylated vitamin D $(25(\mathrm{OH}) \mathrm{D}))$ concentration $<49 \mathrm{nmol} / 1$ at 18 weeks of pregnancy was associated with a significantly increased risk of the offspring being diagnosed with autism. In 2013, Cannell raised the question, "Will vitamin D treat the core symptoms of autism?" (Cannell 2013). Several papers have reported that the answer is yes and the treatment effects are more pronounced in younger children with autism (Feng et al. 2017, Saad et al. 2016).

High doses (5000 IU/day) of vitamin D given to the gravid mothers of autistic siblings really reduce the incidence of autism in the descendants to $5 \%$ in comparison with the common $20 \%$ (Jia et al. 2015, Saad et al. 2016, Stubbs et al. 2016). Autism symptoms and global functioning may improve after vitamin D supplementation. Saad et al. (2016) concluded that vitamin D is inexpensive, readily available and safe and that it may have beneficial effects in ASD subjects, especially when the final serum level is more than $40 \mathrm{ng} / \mathrm{ml}$. However, the studies included small numbers of cases and were uncontrolled. The only double-blinded randomized clinical trial proving the efficacy of vitamin $\mathrm{D}_{3}$ in the dose $300 \mathrm{IU}$ vitamin $\mathrm{D}_{3} / \mathrm{kg} /$ day in 109 ASD patients has been carried out (Saad et al. 2016). Supplementation of vitamin D was well tolerated and the autism symptoms of the ASD children improved significantly, following 4-month vitamin $\mathrm{D}_{3}$ supplementation, but not in the placebo group. In contrary, children with the Williams syndrome, who may have greatly elevated calcitriol levels in early infancy, usually have phenotypes that are the opposite of autism. Children with vitamin D deficient rickets have several autistic markers that apparently disappear with high-dose vitamin $\mathrm{D}$ treatment.

Taken together, majority of studies have shown a negative correlation between the risk for autism and vitamin D levels; however, some studies do not confirm that relationship as reviewed and meta-analyzed by Wang et al. (2016). Discrepancy among the results might be due to the fact that studies reported total vitamin $D$ levels only and did investigate neither VDR nor VDBP.

Studies also did not distinguish between cholecalciferol $\left(\operatorname{vit}_{3}\right)$ and ergocalciferol $\left(\operatorname{vitD}_{2}\right)$ metabolites. It is well known that vitamin $\mathrm{D}_{2}$ which is of 
vegetable origin is $30-50 \%$ less efficient than human/animal vitamin $\mathrm{D}_{3}$. Ingestion of vitD $\mathrm{D}_{2}$ resulted in an increase in serum concentrations of vitD $\mathrm{D}_{2}$ metabolites, accompanied by a comparable decrease in concentrations of vitD $\mathrm{D}_{3}$ metabolites (Biancuzzo et al. 2013). Moreover, the level of vitamins $\mathrm{D}_{2}$ was higher and level of vitamins $\mathrm{D}_{3}$ was lower in patients with other diseases compared to reference ranges for healthy subjects (Mao et al. 2016). It indicates that the origin of vitamin D metabolites should be considered when investigating the effects of this vitamin.

The importance of vitamin D in autism is also supported by genetic studies. A recent paper reported that parental and child alleles of the vitamin D receptor were significantly correlated with risk of autism, as was, in children, an allele of $C Y P 2 R 1$. That gene encodes production of 25-hydroxylase, the enzyme that converts vitamin D to calcidiol 25(OH)D. A recent paper analyzed how vitamin D could affect risk of autism through its effects on tryptophan and serotonin production. The disruption of the serotonergic system is one of the most consistent observations in patients with autism. Serotonin is a neurotransmitter which promotes prosocial behavior and assessment of emotions. Its inadequate levels led to neuroanatomical disorders with cognitive deficits in animal models (Mazer et al. 1997).

\section{Steroids and autism}

The lifetime prevalence of ASD is about $1 \%$. Autism refers higher male incidence with gender ratio 2-4 males to 1 female. According to the "extreme male brain" theory of autism (Baron-Cohen 2002), fetal sex steroids are predicted to be involved in the development of cognition and autism. Elevated levels of selected steroids including progesterone, 17 $\alpha$-hydroxyprogesterone, androstenedione, testosterone and cortisol were observed in amniotic fluid of ASD children (BaronCohen et al. 2015). In agreement with the above theory, a couple of studies on postnatal steroids in autistic patients found significantly higher levels of androgens in saliva (Majewska et al. 2014) and blood samples (Geier and Geier 2007) of autistic children. In contrast, other studies found no relationship between postnatal testosterone concentrations and autistic traits in toddlers (Auyeung et al. 2012, Kung et al. 2016). Together, the later findings arose hypothesis that prenatal (but not postnatal) androgen exposure is associated with the development of autistic traits in young children (Auyeung et al. 2012).

Indeed, gender specific behavior and brain morphology is determined by gonadal steroids during the early development and surprisingly, it is neither testosterone nor other androgens which are responsible for brain masculinization in male fetuses. According to "Aromatization hypothesis", gonadal testosterone diffuses into the brain where is locally aromatized to estradiol and estradiol then initiates the process of masculinization (McCarthy 2008).

Theory of the significance of steroid hormones in autism supports knowledge of another disorder, concretely Smith-Lemli-Opitz syndrome (SLOS). SLOS is a malformation caused by a deficiency of the last step of cholesterol biosynthesis. The enzymatic deficiency manifests biochemically by increased levels of 7-dehydrocholesterol and reduced levels of cholesterol (Porter and Herman 2011). Individuals with SLOS have a high incidence of autism (71-86\% of children with SLOS had ASD) and cholesterol supplementation led to rapid behavioral changes including partial remission of autistic spectrum behaviors. However, cholesterol levels following supplementation did not correlate with presence or severity of autistic symptoms (Sikora et al. 2006). Thus, if ASD is predominant behavioral profile in SLOS and autistic symptoms are improved after cholesterol supplementation, it might be caused by a disruption of cholesterol biosynthesis. It is plausible that the rapid behavioral responses are mediated by neurosteroids derived from cholesterol rather than a cholesterol alone, which does not cross brain blood barrier (Jurevics and Morell 1995).

\section{Other factors and autism}

Different view on the disease suggests autism as a result of oxidative stress. Oxidative stress markers tend to increase whereas levels of the most important antioxidant - glutathione - is decreased in autism (Ghanizadeh et al. 2012). Vitamin D was shown to exert antioxidant effects.

Cannell and Grant (2013) reported that vitamin D plays a major role in the immune system. Evidence exists of neuroglial activation and neuroinflammation in the brain of patients with autism (Cannell and Grant 2013). Vitamin D is important in up-regulating production of antioxidants including glutathione, superoxide dismutase, and thioredoxin reductase (Alvarez et al. 2014). Thus, by genetically 
up-regulating antioxidants, vitamin $\mathrm{D}$ could reduce neuroglial activation and neuroinflammation. Several authors have reported autoimmune conditions in autism including the presence of maternal antibodies to fetal brain tissue (Goines and Van de Water 2010, MartinezCerdeno et al. 2016, Mostafa and Al-Ayadhi 2013). They also found vitamin D blood levels were inversely and strongly associated with the absolute blood level of those antibodies $(\mathrm{R}=-0.86, \mathrm{p}<0.001)$.

Vitamin $\mathrm{D}$ has a major role in inducing T regulatory cells which have an effect on controlling antibodies contributing to autoimmune conditions (Cantorna and Mahon 2004). Thus, the vitamin D induced $\mathrm{T}$ regulatory cells may have a role in reducing autoimmune conditions and protecting the fetus.

\section{Future directions and open questions}

Over the recent years, the prevalence of ASD has abnormally risen for unknown reasons. Specialists speak about epidemic character of the disease, since the incidence has increased to $1: 100$ in children under 8 years of age. The origin of the disease has not yet been identified; however, the correct and early diagnosis and then an expert assistance help to achieve functional status of the patient, in the best cases comparable with that of healthy individuals. Last but not least, the correct diagnosis and cooperation of patient's parents with specialists lead also to reduction of social isolation of the whole patient's family.

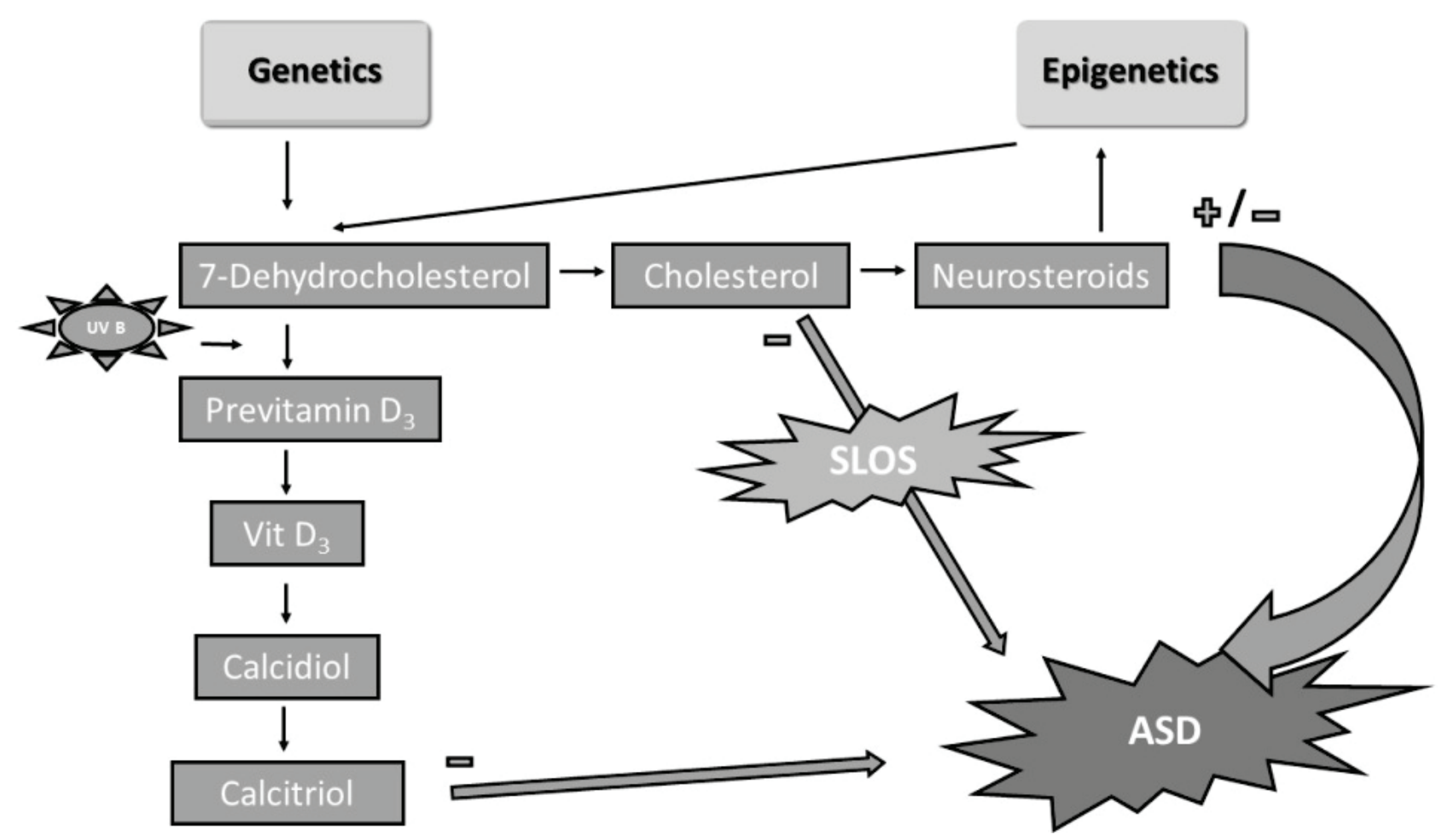

Fig. 1. Potential pathways of vitamin $D$ and steroid hormones action related to ASD. ASD, autistic spectrum disorder; SLOS, Smith-Lemli Opitz syndrome; +/- indicates abnormal levels; - indicates deficiency.

Vitamin D deficiency is undoubtedly a risk factor for autism (Fig. 1), however, it turns out that the mere determination of vitamin $\mathrm{D}$ in blood is not sufficient marker to evaluate the vitamin D status. In cases where levels of VDBP alter, bioavailable vitamin D calculation may help to determine vitamin D status accurately (Kim et al. 2017).

\section{Conflict of Interest}

There is no conflict of interest.

\section{Acknowledgements}

The study was supported by MH CZ - DRO (Institute of Endocrinology - EÚ, 00023761), by the MEYS CR (OP RDE, Excellent research - ENDO.CZ), by grants APVV-15-0045 and APVV-15-0085. 


\section{References}

ALI A, CUI X, EYLES D: Developmental vitamin D deficiency and autism: putative pathogenic mechanisms. $J$ Steroid Biochem Mol Biol in press 2016.

ALVAREZ JA, CHOWDHURY R, JONES DP, MARTIN GS, BRIGHAM KL, BINONGO JN, ZIEGLER TR, TANGPRICHA V: Vitamin D status is independently associated with plasma glutathione and cysteine thiol/disulphide redox status in adults. Clin Endocrinol (Oxf) 81: 458-466, 2014.

AUYEUNG B, AHLUWALIA J, THOMSON L, TAYLOR K, HACKETT G, O'DONNELL KJ, BARON-COHEN S: Prenatal versus postnatal sex steroid hormone effects on autistic traits in children at 18 to 24 months of age. Mol Autism 3: 17, 2012.

BARON-COHEN S: The extreme male brain theory of autism. Trends Cogn Sci 6: 248-254, 2002.

BARON-COHEN S, AUYEUNG B, NORGAARD-PEDERSEN B, HOUGAARD DM, ABDALLAH MW, MELGAARD L, COHEN AS, CHAKRABARTI B, RUTA L, LOMBARDO MV: Elevated fetal steroidogenic activity in autism. Mol Psychiatry 20: 369-376, 2015.

BHAN I, POWE CE, BERG AH, ANKERS E, WENGER JB, KARUMANCHI SA, THADHANI RI: Bioavailable vitamin $\mathrm{D}$ is more tightly linked to mineral metabolism than total vitamin $\mathrm{D}$ in incident hemodialysis patients. Kidney Int 82: 84-89, 2012.

BIANCUZZO RM, CLARKE N, REITZ RE, TRAVISON TG, HOLICK MF: Serum concentrations of 1,25-dihydroxyvitamin D2 and 1,25-dihydroxyvitamin D3 in response to vitamin D2 and vitamin D3 supplementation. J Clin Endocrinol Metab 98: 973-979, 2013.

BIKLE DD, GEE E, HALLORAN B, HADDAD JG: Free 1,25-dihydroxyvitamin D levels in serum from normal subjects, pregnant subjects, and subjects with liver disease. J Clin Invest 74: 1966-1971, 1984.

CANNELL JJ: Autism and vitamin D. Med Hypotheses 70: 750-759, 2008.

CANNELL JJ: Autism, will vitamin D treat core symptoms? Med Hypotheses 81: 195-198, 2013.

CANNELL JJ, GRANT WB: What is the role of vitamin D in autism? Dermatoendocrinol 5: 199-204, 2013.

CANTORNA MT, MAHON BD: Mounting evidence for vitamin D as an environmental factor affecting autoimmune disease prevalence. Exp Biol Med (Maywood) 229: 1136-1142, 2004.

CUI X, GOOCH H, GROVES NJ, SAH P, BURNE TH, EYLES DW, MCGRATH JJ: Vitamin D and the brain: key questions for future research. J Steroid Biochem Mol Biol 148: 305-309, 2015.

ELSABBAGH M, DIVAN G, KOH YJ, KIM YS, KAUCHALI S, MARCIN C, MONTIEL-NAVA C, PATEL V, PAULA CS, WANG C, YASAMY MT, FOMBONNE E: Global prevalence of autism and other pervasive developmental disorders. Autism Res 5: 160-179, 2012.

EYLES DW, SMITH S, KINOBE R, HEWISON M, MCGRATH JJ: Distribution of the vitamin D receptor and 1alphahydroxylase in human brain. $J$ Chem Neuroanat 29: 21-30, 2005.

EYLES DW, BURNE TH, MCGRATH JJ: Vitamin D, effects on brain development, adult brain function and the links between low levels of vitamin D and neuropsychiatric disease. Front Neuroendocrinol 34: 47-64, 2013.

FENG J, SHAN L, DU L, WANG B, LI H, WANG W, WANG T, DONG H, YUE X, XU Z, STAAL WG, JIA F: Clinical improvement following vitamin D3 supplementation in Autism Spectrum Disorder. Nutr Neurosci 20: 284-290, 2017.

FUJIWARA T, MORISAKI N, HONDA Y, SAMPEI M, TANI Y: Chemicals, nutrition, and autism spectrum disorder: a mini-review. Front Neurosci 10: 174, 2016.

GARCION E, WION-BARBOT N, MONTERO-MENEI CN, BERGER F, WION D: New clues about vitamin D functions in the nervous system. Trends Endocrinol Metab 13: 100-105, 2002.

GEIER DA, GEIER MR: A prospective assessment of androgen levels in patients with autistic spectrum disorders: biochemical underpinnings and suggested therapies. Neuro Endocrinol Lett 28: 565-573, 2007.

GHANIZADEH A, AKHONDZADEH S, HORMOZI M, MAKAREM A, ABOTORABI-ZARCHI M, FIROOZABADI A: Glutathione-related factors and oxidative stress in autism, a review. Curr Med Chem 19: 4000-4005, 2012.

GOINES P, VAN DE WATER J: The immune system's role in the biology of autism. Curr Opin Neurol 23: 111-117, 2010. 
GRANT WB: The role of geographical ecological studies in identifying diseases linked to UVB exposure and/or vitamin D. Dermatoendocrinol 8: e1137400, 2016.

GRANT WB, CANNELL JJ: Autism prevalence in the United States with respect to solar UV-B doses: an ecological study. Dermatoendocrinol 5: 159-164, 2013.

GROVES NJ, MCGRATH JJ, BURNE TH: Vitamin D as a neurosteroid affecting the developing and adult brain. Annu Rev Nutr 34: 117-141, 2014.

JIA F, WANG B, SHAN L, XU Z, STAAL WG, DU L: Core symptoms of autism improved after vitamin D supplementation. Pediatrics 135: e196-e198, 2015.

JUREVICS H, MORELL P: Cholesterol for synthesis of myelin is made locally, not imported into brain. J Neurochem 64: 895-901, 1995.

KESBY JP, EYLES DW, BURNE TH, MCGRATH JJ: The effects of vitamin D on brain development and adult brain function. Mol Cell Endocrinol 347: 121-127, 2011.

KIM HJ, JI M, SONG J, MOON HW, HUR M, YUN YM: Clinical utility of measurement of vitamin D-binding protein and calculation of bioavailable vitamin D in assessment of vitamin D status. Ann Lab Med 37: 34-38, 2017.

KOCOVSKA E, FERNELL E, BILLSTEDT E, MINNIS H, GILLBERG C: Vitamin D and autism: clinical review. Res Dev Disabil 33: 1541-1550, 2012.

KUNG KT, CONSTANTINESCU M, BROWNE WV, NOORDERHAVEN RM, HINES M: No relationship between early postnatal testosterone concentrations and autistic traits in 18 to 30-month-old children. Mol Autism 7: 15, 2016.

MAJEWSKA MD, HILL M, URBANOWICZ E, ROK-BUJKO P, BIENKOWSKI P, NAMYSLOWSKA I, MIERZEJEWSKI P: Marked elevation of adrenal steroids, especially androgens, in saliva of prepubertal autistic children. Eur Child Adolesc Psychiatry 23: 485-498, 2014.

MAO X, XING X, XU R, GONG Q, HE Y, LI S, WANG H, LIU C, DING X, NA R, LIU Z, QU Y: Folic acid and vitamins $\mathrm{D}$ and $\mathrm{B} 12$ correlate with homocysteine in Chinese patients with type-2 diabetes mellitus, hypertension, or cardiovascular disease. Medicine (Baltimore) 95: e2652, 2016.

MARTINEZ-CERDENO V, CAMACHO J, FOX E, MILLER E, ARIZA J, KIENZLE D, PLANK K, NOCTOR SC, VAN DE WATER J: Prenatal exposure to autism-specific maternal autoantibodies alters proliferation of cortical neural precursor cells, enlarges brain, and increases neuronal size in adult animals. Cereb Cortex 26: 374-383, 2016.

MAZER C, MUNEYYIRCI J, TAHENY K, RAIO N, BORELLA A, WHITAKER-AZMITIA P: Serotonin depletion during synaptogenesis leads to decreased synaptic density and learning deficits in the adult rat: a possible model of neurodevelopmental disorders with cognitive deficits. Brain Res 760: 68-73, 1997.

MCCARTHY MM: Estradiol and the developing brain. Physiol Rev 88: 91-124, 2008.

MOSTAFA GA, AL-AYADHI LY: The possible relationship between allergic manifestations and elevated serum levels of brain specific auto-antibodies in autistic children. J Neuroimmunol 261: 77-81, 2013.

NAVEILHAN P, NEVEU I, WION D, BRACHET P: 1,25-Dihydroxyvitamin D3, an inducer of glial cell line-derived neurotrophic factor. Neuroreport 7: 2171-2175, 1996.

O'LOAN J, EYLES DW, KESBY J, KO P, MCGRATH JJ, BURNE TH: Vitamin D deficiency during various stages of pregnancy in the rat; its impact on development and behaviour in adult offspring. Psychoneuroendocrinology 32: 227-234, 2007.

OSTATNIKOVA D: Autism From the Neuropsychological Point of View (in Slovak). Comenius University, Bratislava, 2010.

OSTATNIKOVA D: We Have a Child With Autism - a Compass for Parents (in Slovak). VEDA, Publishing House of the Slovak Academy of Science, Bratislava, 2015.

PORTER FD, HERMAN GE: Malformation syndromes caused by disorders of cholesterol synthesis. $J$ Lipid Res 52: 6-34, 2011.

RIMMELZWAAN LM, VAN SCHOOR NM, LIPS P, BERENDSE HW, EEKHOFF EM: Systematic review of the relationship between vitamin D and Parkinson's disease. J Parkinsons Dis 6: 29-37, 2016. 
RINALDI AO, SANSEVERINO I, PURIFICATO C, CORTESE A, MECHELLI R, FRANCISCI S, SALVETTI M, MILLEFIORINI E, GESSANI S, GAUZZI MC: Increased circulating levels of vitamin D binding protein in MS patients. Toxins (Basel) 7: 129-137, 2015.

SAAD K, ABDEL-RAHMAN AA, ELSEROGY YM, AL-ATRAM AA, EL-HOUFEY AA, OTHMAN HA, BJORKLUND G, JIA F, URBINA MA, ABO-ELELA MG, AHMAD FA, ABD EL-BASEER KA, AHMED AE, ABDEL-SALAM AM: Randomized controlled trial of vitamin D supplementation in children with autism spectrum disorder. $J$ Child Psychol Psychiatry in press 2016.

SCHAAF CP, ZOGHBI HY: Solving the autism puzzle a few pieces at a time. Neuron 70: 806-808, 2011.

SIKORA DM, PETTIT-KEKEL K, PENFIELD J, MERKENS LS, STEINER RD: The near universal presence of autism spectrum disorders in children with Smith-Lemli-Opitz syndrome. Am J Med Genet A 140: 1511-1518, 2006.

STUBBS G, HENLEY K, GREEN J: Autism: Will vitamin D supplementation during pregnancy and early childhood reduce the recurrence rate of autism in newborn siblings? Med Hypotheses 88: 74-78, 2016.

WANG T, SHAN L, DU L, FENG J, XU Z, STAAL WG, JIA F: Serum concentration of 25-hydroxyvitamin D in autism spectrum disorder: a systematic review and meta-analysis. Eur Child Adolesc Psychiatry 25: 341-350, 2016. 